\title{
Carnap e o Revisionismo
}

\author{
GELSON Liston \\ Universidade Estadual de Londrina/Capes
}

\begin{abstract}
This paper presents a possible but controversial characterization of two periods in Rudolf Carnap's work: foundationalism and anti-foundationalism. I will argue that even with the identification of two periods, it is possible to argue in favor of the unity of Carnap's work concerning the unity of science and the principle of linguistic tolerance. To do so, I will count on the analysis of some revisionist views advocated by Friedman and Uebel. Therefore I intend to contribute to a discussion that, since the second half of the twentieth century, seemed to have been overcome, but that, at the end of that century is resumed due to the importance of issues such as the unity of science, observability and interpretation of the scientific language for the philosophy of science.
\end{abstract}

Keywords: Foundationalism; anti-foundationalism; unity of science; linguistic tolerance; revisionism.

\section{Introdução}

Alguns autores - como Quine, Ayer e Coffa — vêem a obra de Carnap dividida em dois períodos; um período fundacionalista, identificado com o dogmatismo, e um período antifundacionalista, identificado com o princípio de tolerância linguística e com uma concepção falibilista de conhecimento. Nesse artigo, pretendemos caracterizar de modo mais preciso estes dois períodos (na obra de Carnap), mostrando que mesmo em seu período fundacionalista não há evidências suficientes que demonstrem uma posição eminentemente dogmática; e, então, vamos argumentar em favor da unidade da obra, ${ }^{1}$ conduzida pelo princípio de tolerância linguística e pela tese da unidade da ciência. Desse modo, as alterações são vistas não como rupturas, mas como aperfeiçoamento de um sistema (instrumento) que não pretende ser perfeito, mas que precisa ser constantemente melhorado. Nesse sentido, o próprio sistema construcional, que é a principal referência do fundacionalismo carnapiano e pretende ser apenas um esboço, está sujeito a mudanças, acompanhando o constante desenvolvimento científico.

Desse modo, nosso propósito, aqui, é apresentar e explicar as fases fundacionalista e antifundacionalista do trabalho de Carnap e, então, argumentar em favor da possibilidade de compatibilização das mesmas. Para isso, consideraremos alguns críticos - em especial Uebel e Friedman — chamados de revisionistas de Carnap. A discussão dos problemas levantados por estes autores nos ajuda a melhor situar

Principia 16(1): 99-119 (2012).

Published by NEL — Epistemology and Logic Research Group, Federal University of Santa Catarina (UFSC), Brazil. 
o debate sobre fundacionalismo e antifundacionalismo. Contudo, ela não é decisiva para o argumento acima enunciado, ou seja, a compatibilização dos dois momentos em Carnap se sustenta na ausência desta, pois defendemos que há uma coerência do Carnap fundacionalista com o Carnap antifundacionalista, visto que 'ambos' tendem para os mesmos objetivos: unificar a ciência, eliminar a metafísica e defender a tolerância linguística.

\section{Fundacionalismo e Antifundacionalismo}

O período fundacionalista representa o que aqui iremos chamar de primeira fase da obra de Carnap, principalmente relacionada à idéia de um sistema fundacional construído sobre uma base fenomenológica irrevisável. Aqui, o termo 'irrevisável' terá uma função central para sustentar o argumento que iremos desenvolver na tentativa de compatibilizar a metodologia carnapiana (em seus dois períodos: fundacionalista e antifundacionalista) e, ao mesmo tempo, mostrar que não há dogmatismo na obra de Carnap, mas uma postura que tenta evidenciar a importância da ordem epistêmica na construção de um sistema que pretende unificar a ciência e, consequentemente, eliminar o discurso não-cognitivo ${ }^{2}$ desta. A redução fenomenalista fundamenta-se no pressuposto epistemológico da prioridade epistêmica dos dados dos sentidos e na intersubjetividade das propriedades estruturais. Assim, para Carnap, o conhecimento de um sujeito epistêmico inicia no fluxo da experiência individual e privada, sendo, portanto, subjetivo em sua origem. Contudo, é possível alcançar o conhecimento intersubjetivo através da análise da estrutura da experiência ("certas propriedades estruturais são análogas para todos os fluxos de experiência"). Esta característica das propriedades estruturais permite que os elementos básicos (vivências elementares), que são em si mesmos não-analisáveis (as experiências elementares são unidades básicas mínimas e são tratadas como unidades indivisíveis do sistema), sejam analisados (quasi analysis) a partir de uma relação básica (Rs) chamada de 'Reconhecimento de Similaridade', que possibilita relacionar certa vivência elementar com outra vivência elementar do mesmo fluxo de experiência. Assim, a noção de objetividade científica é construída no próprio sistema. A objetividade fica restrita aos enunciados sobre estruturas, uma vez que o objeto do conhecimento, neste estágio da análise, não é o conteúdo, mas a forma. Assim, os enunciados podem ser representados como entidades estruturais. Isso justifica o 'solipsismo metodológico' que assume como base apenas e tão somente os dados imediatos de um sujeito determinado. A partir do autopsicológico é constituído o 'Eu' e 'Outros sujeitos' numa etapa posterior (cf. Carnap, 1928a, §2 e §66). Este é um dos problemas epistemológicos do Aufbau: mostrar que o conhecimento objetivo é possível, tendo como fundamento experiências individuais subjetivas. A base fenomenológica repre-

Principia 16(1): 99-119 (2012). 
senta apenas uma opção construcional, enquanto que a objetividade do sistema é uma condição para a sua construção racional.

O objetivo de Carnap, portanto, não é justificar a escolha entre, por exemplo, dois sistemas, $\mathrm{x}$ e $\mathrm{y}$, afirmando que um é verdadeiro, enquanto que o outro não, mas que o sistema escolhido é mais eficiente para o que se pretende. É pautado neste princípio que Carnap faz a escolha da base empírica fenomenológica no Aufbau e, do mesmo modo, justifica a alteração para a base empírica fisicalista em "The Unity of Science". Tanto o convencionalismo, quanto o princípio de tolerância estão presentes no Aufbau. E isso não é uma novidade, levando-se em conta a influência do convencionalismo de Poincaré, entre outros, na obra de Carnap. Poincaré é citado, por exemplo, no Aufbau e na Autobiografia Intelectual ${ }^{3}$ como a grande influência em relação à atitude convencionalista.

Assim, quando Carnap explica a escolha de um determinado sistema linguístico de referência, ele o faz no espírito do convencionalismo de Poincaré: Poincaré (1984, p. 54) define os axiomas geométricos como convenções, e afirma:

Nossa escolha, entre todas as convenções possíveis, é guiada por fatos experimentais; mas ela permanece livre e só é limitada pela necessidade de evitar qualquer contradição. É assim que os postulados podem permanecer rigorosamente verdadeiros mesmo quando as leis experimentais que determinaram sua adoção são somente aproximativas.

Em outras palavras, os axiomas da Geometria (não falo dos da aritmética) não passam de definições disfarçadas.

Então, o que devemos pensar da pergunta: a Geometria euclidiana é verdadeira?

Ela não tem nenhum sentido.

É o mesmo que perguntar se o sistema métrico é verdadeiro e as medidas antigas, falsas; se as coordenadas cartesianas são verdadeiras e as polares, falsas. Nenhuma Geometria pode ser mais verdadeira do que outra; o que ela pode, é ser mais cômoda.

No Aufbau, o reducionismo é apresentado como um método necessário para a edificação do sistema construcional. $\mathrm{O}$ mesmo não pode ser dito em relação à base fenomenológica que consiste numa decisão de Carnap. Portanto, a perplexidade inicial que surge da afirmação que estamos fazendo de que o Aufbau é um sistema fundacionalista baseado numa decisão que respeita o princípio de tolerância, deixa de causar espanto e pode, sim, ser consistente. Contudo, com ou sem espanto, essa é uma decisão que serve aos objetivos propostos em seu sistema construcional. Sobre isso, Carnap ressalva que a escolha de uma base, feita de maneira convencional, não exclui a possibilidade de construir um sistema sobre uma base alternativa igualmente legítima, apenas representa um outro tipo de sistema (linguístico). Segundo Carnap, precisamos apenas de uma base que possibilite a verificação dos enunciados científicos, reconstruindo (justificando), assim, o conhecimento. Problemática, 
ou não, a base de evidência desempenha um papel fundamental em qualquer investigação, de modo que ela mesma não pode estar sob investigação. Um dos objetivos do Aufbau é, exatamente, mostrar a possibilidade de construção de um sistema objetivo sobre uma base ontologicamente neutra, e a escolha desta é apenas um aspecto (metodológico) a mais a ser considerado. Essa atitude de Carnap em relação à escolha da linguagem do sistema, formulada como princípio de tolerância em 1934, é uma característica de toda sua obra (cf. 1963a, p. 18).

A atitude convencional de Carnap é manifesta também em sua discussão com Neurath sobre a forma da linguagem protocolar - se os enunciados protocolares devem pertencer, ou não, ao sistema de linguagem (ocorrência interna, ou externa). A posição de Carnap é que a decisão deve ser entendida como um postulado, e a tarefa principal consiste em investigar as consequências e testar a utilidade prática, pois trata-se apenas de "dois diferentes métodos de estruturar a linguagem da ciência, ambos são possíveis e legítimos" (cf. 1932c, p. 457-8). ${ }^{4}$ São duas formas de linguagem: a primeira forma trata os enunciados protocolares como sentenças não-pertencentes ao sistema - ocorrência externa dos protocolos - e tem como principal vantagem permitir maior autonomia ao cientista, que pode decidir sobre a formação do conjunto de tais enunciados. Em alguns casos, se forem sentenças de percepção, de forma arbitrária. A segunda forma (Neurath) trata os enunciados protocolares como sentenças pertencentes ao sistema - ocorrência interna dos protocolos - e tem a vantagem de garantir maior unidade ao sistema, mas a decisão é limitada pela sintaxe do sistema de linguagem em questão. A escolha entre estas duas formas de linguagem caracteriza dois diferentes, mas não contraditórios, tipos de sistemas. Além disso, é importante salientar que nenhum dos dois sistemas permite uma interpretação absolutista de ciência, pois "não há sentenças iniciais absolutas na estrutura da ciência" (Carnap, 1932c, p. 466).

O parágrafo acima revela um problema cuja superação, nas palavras de Coffa, passa exatamente pelo abandono da fase fundacionalista de Carnap:

Carnap não podia sustentar que (a) os protocolos são irrevisáveis, (b) todas as sentenças da linguagem fisicalista são revisáveis, e (c) os protocolos podem ser traduzidos em linguagem fisicalista. Sob a influência dos argumentos de Neurath e de Popper, (a) foi abandonado. (Coffa, 1995, p. 358)

Por uma questão de forma, vamos apresentar uma definição de um sistema epistemológico fundacionalista que, de acordo com nossa análise, caracteriza o que estamos chamando de primeira fase do trabalho de Carnap, o período que antecede a obra de 1934 (The Logical Syntax of Language). Feito isso, apresentaremos uma forma alternativa de sistema epistemológico, um sistema epistemológico falibilista, no caso, o coerentismo.

Def. Uma teoria/sistema qualifica-se como fundacionalista quando subscreve:

Principia 16(1): 99-119 (2012). 
a. Definir um conjunto de enunciados básicos irrevisáveis.

b. Mostrar de que forma podemos construir e reduzir os demais enunciados científicos.

A definição acima é construída a partir de dois requerimentos apresentados por Susan Haack ${ }^{5}$ (1995, p. 14). São eles:

(FD1) Algumas crenças justificadas são básicas; uma crença básica é justificada independentemente do suporte de qualquer outra crença.

e,

(FD2) Todas as outras crenças justificadas são derivadas; uma crença derivada é justificada pelo suporte, direto ou indireto, de uma, ou mais, crença básica.

A partir de $a$ e $b$, temos: A forma pela qual Carnap concebe e desenvolve a estrutura epistemológica do Aufbau e da Unidade da Ciência ${ }^{6}$ pode ser classificada como fundacionalista pelas seguintes razões:

1. - O conhecimento científico está estruturado em um conjunto de enunciados básicos irrevisáveis. Desse modo, Carnap define os fundamentos da ciência empírica.

2. - Carnap justifica a escolha desse conjunto de enunciados básicos pela primazia epistêmica e, então, define o método a ser seguido, estabelecendo, assim, um modelo hierárquico para a construção e justificação dos demais níveis do conhecimento científico - um enunciado se qualifica como científico se puder ser construído e reduzido, de forma direta ou indireta, a esse nível básico de enunciados irrevisáveis. Dessa forma, vemos claramente o caráter normativo e justificacionista de sua epistemologia.

Antes de apresentarmos a definição de um sistema epistemológico coerentista, vale ressaltarmos um pouco mais o tipo de fundacionalismo que caracteriza o modelo epistemológico da primeira fase do trabalho

de Carnap, pois contamos com, pelo menos, dois tipos distintos de fundacionalismos justificacionistas.

O fundacionalismo é um tipo de justificacionismo epistemológico, por ele nos dar uma resposta para uma questão básica da epistemologia: Quais as razões para aceitarmos um determinado sistema teórico, e não outro? A resposta dada por um sistema fundacionalista, como é o caso do sistema carnapiano, é que alguns enunciados básicos são auto-evidentes, de modo que se autojustificam e constituem o fundamento epistemológico de um conjunto de enunciados (não-básicos) que, por sua vez, formam uma teoria. Entretanto, podemos identificar dois tipos de fundacionalismo justificacionista. Um deles, chamado fundacionalismo infalível, afirma que 
os enunciados básicos, além de serem auto-evidentes, são verdadeiros, inatacáveis e, portanto, insubstituíveis. ${ }^{7}$ Uma outra forma de fundacionalismo, mais modesto, afirma apenas que os enunciados básicos fornecem uma razão suficiente para justificar a aceitação de determinado sistema, sem, contudo, se comprometer com a garantia da verdade. Nesse caso, temos um fundacionalismo falível (cf. Lehrer 1990, p. 40).

Em nossa análise, o fundacionalismo carnapiano é identificado com o fundacionalismo falível, vale dizer, no período fundacionalista, seja em sua fase fenomenológica, seja na fisicalista, Carnap está comprometido com uma base composta por enunciados irrevisáveis, mas não infalíveis. ${ }^{8}$ Trata-se, portanto, de uma decisão epistemicamente justificada por razões ou de primazia ou de objetividade linguística.

Do mesmo modo, definiremos um sistema epistemológico coerentista (nos moldes de Neurath) por ser ele um dos mais conhecidos manifestos antifundacionalista da epistemologia contemporânea. Todavia, não estamos identificando o coerentismo com o antifundacionalismo ${ }^{9}$ carnapiano, pois a fase antifundacionalista de Carnap não é coerentista, mas correspondentista e, claro, falilbilista.

Def. Uma teoria/sistema qualifica-se como coerentista quando subscreve:

a. Um enunciado é justificado se pertencer a um conjunto consistente de enunciados.

b. Nenhum enunciado pode ser justificado independentemente da relação com outros enunciados.

Nesse caso, tomamos como referência as seguintes duas definições:

1. - Uma crença é justificada se pertencer a um conjunto coerente de crenças (Haack 1995, p. 17).

2. - Verdade é uma relação de coerência entre um enunciado e dado sistema de enunciados ou crenças; o enunciado $S$ é verdadeiro em relação ao sistema proposicional $\mathrm{K}$, se $\mathrm{S}$ for coerente com $\mathrm{K}$, o que implica ser $\mathrm{S}$ consistente com $\mathrm{K}$ e, se não pertencer a $\mathrm{K}$, deve ampliar este último de modo coerente (ajustando-se bem a K). Em caso contrário, S é falso com referência a K (Da Costa 1999, p. 145).

Diante disso, a teoria coerentista de Neurath pode ser caracterizada, como de fato o foi, como uma teoria antifundacionalista.

Em Carnap, o período fundacionalista está relacionado à tentativa de construir o edifício do conhecimento científico sobre bases sólidas. Essa tentativa daria as bases ou fundamentos para a construção da ciência empírica (unificada). O Aufbau é a principal obra em que Carnap desenvolve essa metodologia no intuito de definir os 
enunciados básicos e fundamentais a partir dos quais os demais enunciados e conceitos que representam a ciência unificada serão construídos. O fundacionalismo, nesse sistema, é complementado pelo reducionismo radical que pretendia justificar todo o conhecimento empírico reduzindo-o ao imediatamente dado, com o auxílio da lógica. A construção de um método consistente que possa garantir esses objetivos é a principal função da epistemologia, que fica, dessa forma, restrita ao campo da justificação. Este é o sentido que Carnap expressa no primeiro parágrafo de "Pseudoproblemas na Filosofia", ou seja, indica de que forma o método de reconstrução racional pretende a justificação epistêmica;

O objetivo da epistemologia é a formulação de um método para a justificação das cognições. [...] Tal justificação, contudo, não é absoluta, mas relativa; justifica-se o conteúdo de uma certa cognição relacionando-a com os conteúdos de outras cognições que se supõem serem válidas. Deste modo, um conteúdo é "reduzido" a outro, ou é "epistemologicamente analisado".

Para analisar os conteúdos das cognições, a epistemologia deve investigar os objetos (conceitos) da ciência (empírica) em suas várias subdivisões (as ciências naturais e culturais). Deve averiguar quais são os outros objetos que se podem "reduzir" a cognições de todo objeto dado. Logo, empreendese "uma análise" dos objetos em que se reduzem os objetos "superiores" aos "inferiores". Chamam-se objetos "(epistemologicamente) fundamentais" aqueles objetos que não podem ser mais reduzidos. (Carnap 1928b, p. 305, itálicos nossos)

Este parágrafo nos mostra claramente que o tipo de justificação proposta por Carnap não é absoluta, mas relativa a uma base supostamente válida, ou aceita como válida a partir de um sistema construcional. Nesse sentido, a reconstrução racional dos conceitos científicos envolve um aspecto convencional, lógico e empírico: o sistema construcional é constituído sobre uma base escolhida convencionalmente; a relação dos conceitos é puramente formal; o controle empírico é estabelecido pelas condições de possibilidade de atribuição de valor verdade.

E no Aufbau, Carnap afirma o seguinte:

Temos repetidamente apontado que a formação do sistema construcional como um todo é a tarefa da ciência unificada. [...] Como podemos determinar o objetivo da ciência unificada a partir da teoria construcional? O objetivo da ciência consiste em encontrar e ordenar os enunciados verdadeiros acerca dos objetos da cognição. (Carnap 1928a, § 179)

O período antifundacionalista - a partir de 1934 - representa, em nossa interpretação, um avanço (sem rupturas) da metodologia carnapiana, aprimorando assim o instrumental de análise do conhecimento científico e se aproximando mais da própria prática científica. Esse período é marcado, principalmente, pelo abandono do verificacionismo radical, uma posição lógica e empiricamente insustentável, ${ }^{10}$ e pela 
aceitação de uma base empírica revisável. Além disso, devemos destacar a grande importância do princípio de tolerância na interpretação das formas linguísticas.

A concretização do ideal carnapiano de construção de um sistema que possa unificar a ciência, seja este fundacionalista ou não, submete-se à possibilidade de construir tal sistema a partir de uma linguagem universal e intersubjetiva na qual enunciados e leis possam ser expressos e interpretados. Tal preocupação servirá de base para entendermos os períodos fundacionalista e antifundacionalista em Carnap, bem como a importante contribuição de Neurath na liberalização linguística de Carnap rumo ao fisicalismo antifundacionalista.

Neurath enaltece a teoria construcional de Carnap no que diz respeito à tentativa de providenciar uma base para a ciência unificada, mas não aceita sua opção fenomenalista, dependente das experiências imediatas e individuais de um sujeito epistêmico, e sugere, não apenas a alteração dessa base (alteração meramente linguística), mas uma decisão metodológica que privilegie e possibilite uma reconstrução constante dela, enriquecendo-a tanto quanto possível. Portanto, a crítica de Neurath ao solipsismo metodológico de Carnap deve ser vista também como uma crítica ao fundacionalismo, pois a simples mudança de uma base fenomenológica para uma base fisicalista é compatível com a teoria construcional fundacionalista, uma vez que Carnap reconhece tal possibilidade no Aufbau.

Em seu artigo de 1930, "The Old and the New Logic", Carnap retoma esta questão e afirma que a opção metodológica por uma base positivista, ou por uma base materialista não constitui sistemas contraditórios, e qualquer um destes é compatível com a tese da concepção científica do mundo, pois elimina ou a tese metafísica sobre a realidade do dado, ou a tese metafísica da realidade do mundo físico, mas admite que o modo de validação do conhecimento científico por redução ao físico é o único que torna possível o conhecimento intersubjetivo (cf. p. 144). Tal reconhecimento, ${ }^{11}$ por parte de Carnap, é um passo decisivo rumo ao fisicalismo, pois passa a evidenciar a linguagem fisicalista como a forma de linguagem para a ciência unificada, superando, então, a privacidade da linguagem solipsista, em razão de que a linguagem da ciência deve ser universal e permitir o controle intersubjetivo dos enunciados. Contudo, mesmo em sua fase fisicalista, Carnap assume a linguagem protocolar fenomenalista como uma parte da linguagem fisicalista, ou seja, a tese da universalidade (capacidade representacional) da linguagem fisicalista demanda que tais enunciados possam ser traduzidos, ou interpretados em linguagem fisicalista (cf. 1932a, p. 76 e p. 88). Mas a posição de Carnap em relação a esta tarefa admite a dificuldade de uma tradução sem o uso de inferências hipotéticas. Este é um problema intimamente relacionado à atribuição de significado empírico às leis teóricas.

Portanto, já em sua fase fisicalista, Carnap enfrenta, de uma maneira mais eficaz, a questão do absolutismo em relação aos enunciados que formam a base empírica da ciência unificada, aceita a posição de Neurath (e também de Popper) sobre a 
possibilidade de revisão de toda e qualquer sentença, e defende o convencionalismo linguístico para todas as formas de sentenças, renunciando a qualquer tipo de absolutismo e adotando uma postura falibilista, já que toda sentença é uma hipótese (cf. 1934, p. 318).

No artigo "On Protocol Sentences", publicado no mesmo ano do "The Unity of Science", Carnap, ao analisar os resquícios de absolutismo em algumas teorias do conhecimento, faz uma explícita referência crítica a uma forma de absolutismo ainda presente no Positivismo Lógico, referindo-se especificamente às 'sentenças elementares'. Trata-se de uma autocrítica e, ao mesmo tempo, do reconhecimento da importância de Neurath que, decisivamente, se posicionou contra esse tipo de absolutismo, rejeitando a irrevisibilidade das sentenças protocolares:

Se uma sentença protocolar tentativa não é consistente com as demais sentenças protocolares ou com as outras sentenças concretas admitidas, então temos de escolher: modificar as sentenças protocolares ou o grupo das sentenças concretas em questão, ou modificar o grupo de leis que permitiram derivar tais sentenças. (Carnap 1932c, p. 467)

\section{Revisionismo}

A partir da perspectiva tolerante de Carnap, marcada pelo abandono da epistemologia fundacionalista, consideraremos alguns críticos que discordariam do argumento aqui defendido e afirmariam que tal leitura do positivismo lógico torna obscura a tentativa do próprio movimento de propor uma revolução no método filosófico e, portanto, negam a existência de um período fundacionalista na obra de Carnap, oferecendo, assim, uma nova leitura. Referimo-nos a Thomas Uebel e Michael Friedman. Outro crítico que podemos citar é Stadler (2003, p. xi-xii), que, por sua vez, reconhece a dificuldade de providenciar uma descrição representativa do Círculo de Viena em sua totalidade. Segundo Stadler, algumas diferenças são facilmente vistas, como é o caso de algumas opções epistemológicas: fenomenalismo-fisicalismo, coerentismo-correspondentismo, entre outras. Mas a questão que se impõe é: "é possível encontrar um tipo de acordo básico, algo que unifique os membros do Círculo de Viena?" Entre outras orientações, Stadler aponta "um tipo de epistemologia falibilista que se opõe a qualquer tipo de sistema fundacionalista".

Uebel (1996) afirma (a) ser possível uma interpretação antifundacionalista epistemologicamente consistente para os três principais protagonistas do Círculo de Viena, Schlick, Carnap e Neurath, e (b) chama a atenção para o fato de que o Círculo de Viena não era um movimento monolítico de filósofos fundacionalistas (p. 415). Em relação às duas teses de Uebel, podemos afirmar que ele está correto em relação a (b) e que, de fato, não há nenhuma novidade nisso. Afirmamos isso com base no 
próprio argumento de Uebel, a análise do debate sobre as sentenças protocolares na década de 30. Todavia, se nosso argumento estiver correto, a tese (a) não se sustentaria, uma vez que podemos argumentar em favor de dois períodos distintos na obra de Carnap.

Como estratégia de argumentação, faremos uma análise crítica de (a), pois, assim, responderemos também a (b). Nossa análise se concentrará fundamentalmente em Carnap.

Ao analisar o solipsismo metodológico no Aufbau, Uebel (1996, p. 424) aceita que "em alguns aspectos, o Aufbau é compatível com o fundacionalismo"; contudo, afirma Uebel que, em sua reconstrução conceitual, Carnap não dispõe de nenhum tipo de certeza incondicional, por depender de fatores contingenciais - a verdade de algumas leis científicas. Além disso, Uebel utiliza como argumento em favor de sua posição a própria tese de Carnap em relação à escolha da base do sistema construcional: que a escolha desta é convencional, deixando em aberto a possibilidade de uma outra base ser escolhida, por exemplo, uma base fisicalista. Nesse aspecto, Uebel realmente está certo, mas esquece de comentar o fato de que a escolha de uma base diferente, conquanto possível, representaria um outro sistema, que também pode ser fundacionalista, como, de fato, é o sistema fisicalista reducionista, já que o teste dos enunciados que formam determinado sistema é feito por meio de suas relações lógicas com os enunciados que formam a base empírica do sistema, enunciados que, por sua vez, não necessitam de justificação.

Em relação à falta de certezas incondicionais no sistema construcional carnapiano, Uebel, uma vez mais, está correto. Todavia, esta busca não era uma preocupação de Carnap e, também, não é a falta de tais certezas que inviabiliza a construção de um sistema fundacionalista em intenção, pois se definirmos o fundacionalismo como um sistema baseado em verdades últimas e inabaláveis, então sua defesa em Carnap torna-se difícil, uma vez que não dispomos de um critério para discernir a verdade de forma inequívoca, e as possibilidades de erros são inúmeras. Mas o fundacionalismo não pressupõe, necessariamente, que as sentenças básicas sejam absolutamente verdadeiras $^{12}$ para suportar outras sentenças. O que Carnap faz em seu sistema construcional é definir uma base, cujas sentenças são irrevisáveis, a partir da qual a ciência possa ser construída. Com isso, Carnap entende que a verificação de uma lei, ou um sistema de sentenças, significa a constatação de que ela está em conformidade com as sentenças protocolares; mas, por sua vez, as sentenças protocolares não requerem verificação. Deste modo, uma vez aceito o sistema proposto, o fundacionalismo é uma característica dele. É desse modo que afirmamos uma fase fundacionalista em Carnap:

Os enunciados na linguagem-protocolar são enunciados protocolares, isto é, enunciados que não necessitam de justificação e servem de fundamento para todos os enunciados restantes da ciência. (Carnap, 1932a, p. 45)

Principia 16(1): 99-119 (2012). 
É importante notar, todavia, que esta passagem serve para definir os enunciados protocolares, postulados que possibilitam a verificação. Contudo, a falta de um critério para distinguir enunciados protocolares de enunciados não-protocolares impossibilita a caracterização precisa de uma linguagem protocolar, de tal modo que Carnap assume esta dificuldade e lança mão de exemplos de enunciados protocolares que tenham "aproximadamente o seguinte tipo: Há um cubo vermelho sobre a mesa" (cf. 1932a, pp. 42ss). Posteriormente, esta distinção torna-se um pouco mais clara devido à utilização de outra distinção: aquela entre observáveis e inobserváveis. Assim, um enunciado protocolar é caracterizado pela condição de conter apenas predicados físicos observáveis, termos que se referem a fenômenos que podem ser diretamente observados. Além disso, Carnap esclarece a questão do confronto entre enunciados e enunciados previamente aceitos e de enunciados com fatos (cf. Carnap 1949, p. 125). Mesmo assim, a aceitação é convencional, pois não há uma regra geral para determinar a decisão.

Assim sendo, o conhecimento está alicerçado em algum tipo de fundamento que serve de base para sua justificação. Essa base, por sua vez, se autojustifica, ela se mantém sem o suporte de outras sentenças. As sentenças básicas têm, portanto, um status epistemológico privilegiado. Assim, entendemos que a alteração da base empírica, feita por Carnap, o que significa uma mudança de sistema (escrito em outra linguagem), deve ser analisada pelo viés da objetividade científica, e não por uma atitude declaradamente antifundacionalista, que surge como consequência do fracasso na busca de sentenças observacionais definitivas para formar a base de certeza da construção do conhecimento científico. Para sustentar esta interpretação, contamos com a análise histórica do Círculo de Viena feita pelo próprio Carnap, e não por críticos que, segundo Uebel e também Friedman, dificultaram uma interpretação imparcial, apresentando uma visão estereotipada do movimento. Friedman (1999, p. 02) afirma "talvez o maior equívoco da visão estereotipada do Positivismo Lógico é a caracterização deste enquanto uma versão do 'fundacionalismo' filosófico". Segundo Friedman, o Aufbau seria a principal referência dessa leitura pela tentativa de Carnap em providenciar a justificação epistemológica da ciência - "supostamente, o Aufbau é o trabalho mais representativo da epistemologia fundacionalista" -, e argumenta:

É verdade que o Aufbau pretende uma redução fenomenalista de todos os conceitos da ciência aos dados imediatos da experiência. Contudo, o objetivo da construção tem pouco, se é que tem algo, de próximo do fundacionalismo tradicional. Primeiro, Carnap não mostra nenhum interesse pelos objetivos que motivam o ceticismo filosófico, como, por exemplo, Russell em Our Knowledge of the External World (1914), tampouco o texto do Aufbau está comprometido com o vocabulário tradicional de 'certeza', 'dúvida', 'justificação', e assim por diante. Segundo, e mais importante, Carnap

Principia 16(1): 99-119 (2012). 
é perfeitamente explícito quanto à dependência da construção particular que ele usa, em relação aos atuais 'resultados das ciências empíricas' (§122) e quanto ao sistema construcional particular que ele apresenta é melhor visto como uma 'reconstrução racional' dos processos (empíricos) reais do conhecimento (§100). (Friedman 1999, p. 4)

Sobre a metodologia reducionista, Friedman (1991, p. 508) comenta que a estratégia adotada por Carnap, em sua tentativa de reconstrução racional do conhecimento científico por meio da redução de todos os conceitos da ciência aos dados imediatos da experiência, não representa uma atitude fundacionalista. Os motivos apresentados por Friedman são que Carnap se distancia das atitudes de um fundacionalista tradicional, que busca certezas e, com elas, busca responder aos céticos. Além disso, o sistema construcional dependia dos avanços recentes da lógica e de ciências empíricas como a psicologia comportamental.

Entretanto, para realizar uma investigação epistemológica que conduza a um sistema integrado da ciência unificada, Carnap (1928b, p. 314) pressupõe apenas que o procedimento de justificação epistemológica seja válido:

Ao retroceder até o método de uma ciência especial a fim de decidir sobre uma dada questão epistemológica, não introduzimos essa ciência especial como um pressuposto para um sistema válido de conhecimento. Pois ainda não estamos preocupados com a questão de saber se as (supostas) cognições da ciência especial devem ser consideradas corretas ou não, mas com a questão de saber se vale ou não a relação de dependência epistemológica entre os objetos dados do campo.

No Aufbau ( $\S$ 67), ao falar da importância de analisar o fluxo da experiência, Carnap comenta que as investigações psicológicas em conexão com a teoria da Gestalt "tem confirmado mais e mais que a impressão total é epistemicamente primária, e que as assim chamadas sensações individuais são derivadas apenas através de abstrações". O que nos parece é que Carnap está tentando justificar a base do sistema, reforçando, uma vez mais, a idéia da primazia epistêmica.

Friedman também se posiciona em relação à concepção de filosofia defendida pelo positivismo lógico, afirmando que o movimento não sustenta uma concepção fundacionalista da filosofia. Essa constatação de Friedman é correta, mas desnecessária, uma vez que na concepção científica do mundo, proposta pelo Círculo de Viena, os problemas filosóficos tradicionais são vistos como pseudoproblemas, e não cabe ao filósofo propor teses filosóficas, mas fazer da filosofia um método lógicolinguístico de análise. Portanto, a filosofia não está sujeita ao mesmo tipo de análise que se propõe aos enunciados do sistema construcional; mas, antes, é ela mesma que possibilita tal análise.

Todavia, não é esse o tipo de fundacionalismo a que estamos aqui nos referindo, mas a um tipo de procedimento que define e assume uma base segura para a cons- 
trução de um edifício sólido, não inabalável. A busca por estes pontos de partida cumpre o objetivo do projeto epistemológico de Carnap em seu sistema construcional. Assim, podemos claramente identificar no Aufbau uma metodologia de base fundacionalista marcada por uma atitude convencional e não dogmática, uma vez que a justificação apresentada é de cunho prático, e não teórico. Tal identificação encontra respaldo na própria autocrítica de Carnap em sua autobiografia:

Sob a influência de alguns filósofos, especialmente Mach e Russell, no Aufbau eu considerava a linguagem fenomenalista como a melhor para a análise filosófica do conhecimento. Eu acreditava que a tarefa da filosofia consistia na redução de todo o conhecimento a uma base de certeza. Desde que a maior parte do conhecimento certo é a do imediatamente dado, enquanto que o conhecimento dos objetos materiais é derivativo e menos certo, parecia que o filósofo deveria empregar uma linguagem que usasse dados do sentido como base. Nas discussões de Viena, minha atitude mudou gradualmente rumo a uma preferência para a linguagem fisicalista. (Carnap 1963a, p. 50, itálicos nossos)

E, ao analisar a liberalização do empirismo a partir do abandono do verificacionismo radical - radical no sentido de que os enunciados deveriam ser reduzidos a uma conjunção finita de sentenças protocolares - Carnap e os integrantes do Círculo de Viena não exigiam a possibilidade real de determinação da verdade ou da falsidade dos enunciados. Carnap faz questão de ressaltar este aspecto do verificacionismo ao analisar o desenvolvimento do empirismo:

Entretanto, mesmo na época do Círculo de Viena, não interpretávamos o princípio de verificabilidade neste sentido estrito. Enfatizávamos que o princípio requeria não a possibilidade real de determinação da verdade ou da falsidade, mas somente a possibilidade em princípio. (Carnap 1975b, p. 240)

$\mathrm{Na}$ "Unidade da Ciência", essa interpretação é bastante clara, principalmente em relação ao caráter hipotético das leis (cf. p. 48-9). Portanto, Carnap comenta sobre as dificuldades de conciliar uma posição metodológica tão rígida, apresentada no Aufbau, com uma concepção de método científico que, dada a importância e a função das hipóteses na ciência, privilegia o caráter hipotético das leis da natureza (e também o caráter aberto dos conceitos científicos, ou seja, a incompletude da interpretação) - posição esta influenciada por Poincaré e Duhem, e, no Círculo, retomada por Neurath que sempre rejeitou a tese de que o conhecimento científico pudesse ser construído sobre uma base indubitável ${ }^{13}$ — e afirma:

Nós assumimos que havia uma base sólida de conhecimento, o conhecimento do imediatamente dado, que era indubitável. Qualquer outro tipo de conhecimento era considerado sustentado por essa base e, portanto, igualmente decidível com certeza. (Carnap 1963a, p. 57, itálicos nosso)

Principia 16(1): 99-119 (2012). 
Friedman discute essas passagens da autobiografia e defende apenas que a linguagem fundacionalista é utilizada retrospectivamente, já que em nenhum momento Carnap utilizou o vocabulário fundacionalista no Aufbau (cf. 1999, p. 119), de modo que não representa suas motivações iniciais. $\mathrm{O}$ argumento de Friedman é que Carnap não estava descrevendo as reais motivações do Aufbau, ${ }^{14}$ e sim como este foi inicialmente entendido no Círculo de Viena, principalmente para compreender a alteração gradual da linguagem fenomenológica para a linguagem fisicalista, e o debate sobre as sentenças protocolares. Deste modo, temos a seguinte leitura de Friedman:

Por conseguinte, todas as evidências sugerem que, quando Carnap usa a linguagem empirista antifundacionalista em sua 'Intellectual Autobiography', ele não está descrevendo realmente sua própria visão - e ele certamente não está descrevendo as reais motivações do Aufbau. Ele está, antes, retratando, a dialética filosófica entre o 'right wing' e o 'left wing' do Círculo, de um modo particularmente claro e dramático. Entretanto, não há dúvidas de que o Aufbau — particularmente da forma como foi lido por Schlick e Waismann — desempenhou uma função central nesta dialética. Carnap, por si mesmo, não fez nem um movimento rumo a um fundacionalismo epistemológico. A posição de Carnap, todavia, muda significativamente após o confronto com Neurath no debate sobre as sentenças protocolares, mas esta mudança não consiste no abandono da epistemologia fundacionalista em particular (com a qual ele nunca se envolveu). (Friedman 1999, pp. 151-2)

De qualquer modo, Friedman afirma que a mudança de Carnap em relação à linguagem e às sentenças protocolares não representa o abandono do aparente fundacionalismo, e sim o modo pelo qual Carnap enfrenta o problema da teoria construcional, ou seja, como reconstruir racionalmente o conhecimento objetivo a partir da experiência privada (cf. 1999, p. 145ss).

Para Friedman, podemos encontrar uma explicação para a equivocada leitura do Aufbau a partir da influência do Tractatus de Wittgenstein, pois

O Círculo de Viena via no Tractatus uma concepção empirista-fundacionalista de significado - e esta compreensão do Tractatus - foi adotada especialmente por Waismann e Schlick. Deste modo, foi inteiramente natural ler o Aufbau de Carnap como uma realização da teoria do significado do Tractatus. (Friedman, 1999, p. 148)

Enfim, afirmamos que as mudanças não significam uma ruptura nas posições carnapianas, ou seja, não há uma mudança radical na obra de Carnap. As alterações de 1928 a 1966 são compatíveis com a concepção científica do mundo advogada por Carnap. Contamos, para isso, além dos textos aqui analisados, com as notas (1957) de Carnap para a edição de alguns de seus artigos no Logical Positivism editado por Ayer (1959). Nessas notas, Carnap faz apenas alguns esclarecimentos terminológicos 
e comenta sobre a liberalização do empirismo (verificacionismo - confirmacionismo). Mas Carnap faz questão de afirmar que o conteúdo essencial é mantido intacto, principalmente o fisicalismo e a tese da unidade da ciência (cf. Ayer 1959, p. 146 e 198).

Como comentamos acima, o princípio de tolerância representa o núcleo de nossa leitura. Entretanto, tal princípio não pode ser interpretado como um princípio de complacência, que implique uma posição convencionalista, pois ele se refere apenas à escolha da estrutura da linguagem, e não ao conteúdo das sentenças sintéticas (cf. 1963b, p. 864). Para Carnap, a definição de uma estrutura linguística é fundamental, pois não podemos justificar um julgamento considerando-o individualmente, ou seja, a justificação é relativa a uma estrutura linguística. Contudo, em relação aos enunciados sintéticos, nenhum julgamento é independente dos resultados empíricos. O confronto das sentenças básicas com os fatos (primeira operação) (cf. 1949, p. 125) é indispensável para o teste científico e não pode ser rejeitado pelos empiristas. Daí o motivo de Carnap ressaltar o componente não-convencional, objetivo, dos fatos, e esclarecer que o componente convencional diz respeito à falta de uma regra geral para determinar nossa decisão quanto à aceitação ou rejeição de sentenças, ou seja, é metodologicamente impossível testar uma sentença singular hipotética isolada (cf. 1934, p. 318), mas isso não significa que a própria decisão e a questão da verdade sejam convencionais (cf. 1936-7, p. 426), e que, com isso, Carnap estaria dissolvendo a distinção convencional e factual; empírico e não-empírico (cf. Friedman 1999, p. 70).

Em seu trabalho de 1966, p. 59, Carnap discute a importância das decisões convencionais e enfatiza os riscos de uma interpretação convencionalista radical, pois as convenções realmente desempenham uma função fundamental na construção de um sistema científico, principalmente no que diz respeito à testabilidade: "não devemos negligenciar esta função. Por outro lado, devemos ser cuidadosos para não superestimar o aspecto convencional". Neste caso, leiamos Carnap.

Alguns filósofos cometeram erros desta natureza, adotando uma visão completamente convencionalista, que eu considero um equívoco. Um deles [Hugo Dingler] afirma que todos os conceitos, e igualmente as leis da ciência, são uma questão de convenção. [... ] Devemos estar atentos para o componente empírico e a função que ele desempenha. [... Temos que acomodar nosso sistema aos fatos da natureza.

O conhecimento factual é necessário para que as decisões convencionais não sejam completamente arbitrárias e entrem em conflito com os fatos da natureza.

E no $\S 179$ do Aufbau, é muito clara a posição de Carnap sobre a importância da verificabilidade como um critério de significado para os enunciados; por ela Carnap afirma que a verificação significa o teste sobre a base da experiência. Para Carnap, este é o componente empírico, não-convencional, já que a formação do sistema 
construcional é convencional. Além disso, Carnap reserva todo o $\S 7$ dos Pseudoproblems, publicado no mesmo ano, para explicar a importância do conteúdo factual enquanto critério de significatividade dos enunciados. Diante dessas evidências, Friedman (1999) supõe, em uma nota da p. 148, que esta seção tenha sido incluída após Carnap ter retornado a Viena. A partir dessa posição de Friedman, entendemos os argumentos que ele apresenta para sustentar que Carnap não defende uma posição empirista fundacionalista no Aufbau, pois se analisarmos o sistema construcional apenas como um sistema puramente formal e, portanto, convencional, de fato, a noção de ostensão não tem nenhuma função. Se isso for suficiente, então podemos afirmar que a experiência não desempenha função alguma no Aufbau. Daí a importância de levarmos em conta as investigações sobre as propriedades não-construcionais do Aufbau, que, segundo o próprio Carnap, se dão através da experiência:

O primeiro objetivo, então, é a construção dos objetos; ele é seguido por um segundo objetivo, isto é, a investigação das propriedades não-construcionais e relações dos objetos. O primeiro objetivo é alcançado por meio de convenções; o segundo, entretanto, através da experiência (na visão da teoria construcional, não há outros componentes além desses dois, o convencional e o empírico; assim, não há sintético a priori). (§179)

É verdade que no Aufbau a teoria construcional, a unidade da ciência e a objetividade científica são temas interligados, pois o objetivo de Carnap é uma descrição puramente estrutural do conhecimento científico, de modo que todo conceito científico tenha o seu lugar nesse sistema estruturalmente unificado, sem a necessidade de definições ostensivas. É neste ponto que Friedman sustenta o seguinte argumento sobre o Aufbau:

O Aufbau tem menos afinidade com o empirismo tradicional do que com a concepção kantiana e neo-kantiana de conhecimento. [...] todavia, a mais importante concepção carnapiana de conhecimento e significado é kantiana — e, de fato, completamente oposta ao empirismo tradicional — ela é muito mais holística do que atomística. (Friedman 1999, p. 98-9).

\section{Conclusão}

De fato, o argumento acima está muito bem fundamentado, mas permanece uma dúvida: Qual a função do verificacionismo no Aufbau, e mais, que motivos teria Carnap ao citar Hume e Wittgenstein como duas grandes influências de seu trabalho? Seria demasiadamente estranho afirmar a influência do atomismo lógico de Wittgenstein e Russell? No caso de Russell, a influência nos parece bastante clara, pois a sua versão do atomismo tem um caráter epistemológico baseado nos dados dos sentidos (embora a análise seja lógica), e uma teoria correspondentista da verdade em que a

Principia 16(1): 99-119 (2012). 
verdade de uma proposição depende de algum fator externo - a congruência entre a estrutura da proposição e do fato correspondente. ${ }^{15}$

Além disso, teria algum sentido Quine utilizar uma concepção holística para, exatamente, criticar a distinção entre analítico e sintético? E, principalmente, o dogma reducionista? Afinal, qual o sentido da conhecida crítica de Quine à Carnap:

O dogma do reducionismo sobrevive na suposição de que cada enunciado, tomado isoladamente de seus companheiros, pode admitir confirmação ou infirmação de algum modo. Minha contraproposta, resultando essencialmente da doutrina do mundo físico de Carnap no Aufbau, é que nossos enunciados sobre o mundo exterior enfrentam o tribunal da experiência sensível não individualmente, mas apenas como um corpo organizado.

O dogma do reducionismo, mesmo em sua forma atenuada, está intimamente ligado a outro dogma — o de que existe uma separação entre o analítico e o sintético. Nós mesmos nos vimos, na realidade, levados deste último ao primeiro problema através da teoria verificacionista do significado. Mais diretamente, um dogma claramente suporta o outro neste sentido: enquanto se considera significante em geral falar de confirmação ou infirmação de um enunciado, parecerá igualmente significante falar de um tipo limite de enunciado que é confirmado vacuamente ipso facto, aconteça o que acontecer; e tal enunciado é analítico. (Quine 1985, p. 245)

Seguindo a linha de argumentação de Friedman, temos a seguinte resposta, da qual discordamos:

A objetividade científica, de acordo com Carnap, requer precisamente deste modo um sistema unificado de descrições definidas de um modo puramente estrutural; a redução fenomenalista de todos os conceitos ao dado não é, de modo algum, essencial. (Friedman 1999, p. 1001)

Discordamos exatamente pelo fato de que se o sistema construcional carnapiano é fundacionalista, como, de fato, estamos afirmando, diferentemente de Friedman e Uebel, entre outros revisionistas, então a base empírica e o método de redução de conceitos têm uma função essencial. ${ }^{16} \mathrm{O}$ que não é essencial é o tipo de base empírica, já que a escolha poderia, sem problemas, ser diferente. Além disso, o que justificaria o esforço de Carnap em substituir a linguagem fenomenalista para uma linguagem fisicalista, bem como a troca do princípio de verificabilidade pelo princípio de confirmabilidade, ambos interpretados como uma atitude empirista anti-metafísica de Carnap? Outra importante questão a ser levantada é a função da unidade linguística, que serve de suporte para a unidade da ciência. Nesse caso, não podemos, de forma alguma, esquecer o trabalho de Carnap relacionado à liberalização do empirismo, desde o Aufbau (1928) até o seu An Introduction to the Philosophy of Science (1966), ou seja, a preocupação carnapiana em construir uma linguagem empirista 
unificada como base para a unificação conceitual da ciência. Isso justifica nossa insistência em analisar o trabalho de Carnap como um todo. Uma análise feita a partir de recortes permite, é claro, interpretações controversas.

\section{Referências}

Ayer, A. J. 1952. Language, Truth and Logic. New York: Dover Publication. 1959. Logical Positivism. New York: The Free Press.

Carnap, R. 1928b. Pseudoproblems in Philosophy. Berkeley e Los Angeles: University of California Press.

-1952. Quine on Analyticity. In: Carnap 1990.

- 1966. An Introduction to the Philosophy of Science. New York: Basic Books, Inc.

—. 1975a [1950]. Empirismo, Semântica e Ontologia. São Paulo: Abril Cultural, Os Pensadores.

—. 1963c [1935]. Filosofía Y Sintaxis Lógica. México: Universidad Nacional Autónoma. 1959a [1932]. The Elimination of Metaphysics Through the Logical Analysis of Language. In: Ayer 1959.

—. 1963a. Intellectual Autobiography. In: Schilpp 1963.

- 1975b [1956]. O Caráter Metodológico dos Conceitos Teóricos. In: Coleção Os Pensadores. São Paulo: Nova Cultural, 1988.

—. 1932c. On Protocol Sentences. Nous 21: 457-70 (1987). In: Sarkar 1996.

—. 1963b. Replies and Systematic Exposition. In: Schilpp 1963, pp. 859-1013.

- 1936-7. Testability and Meaning. Philosophy of Science 3: 1-40; 4: 420-71.

-1932a. The Unity of Science. Bristol: Thoemmes Press.

- 1934. The Logical Syntax of Language. New Jersey: Littlefield, Adams \& Company.

- 1928a. The Logical Structure of the World. Berkeley e Los Angeles: University of California Press.

- 1930. The Old and The New Logic. In: Ayer 1959.

— 1949 [1936]. Truth and Confirmation. In: Feigl, H. and Sellars, W. (eds.) Reading in Philosophical Analysis. New York, Appleton-Century-Crofts.

—. et. al. 1986 [1929]. A Concepção Científica do Mundo - O Círculo de Viena. Cadernos de História e Filosofia da Ciência 10: 5-20.

Cirera, R. 1994. Carnap and the Vienna Circle: Empiricism and Logical Syntax. Amsterdam, Atlanta: Rodopi.

Coffa, J. A. 1995. The Semantic Tradition from Kant to Carnap. Cambridge: Cambridge University.

Da Costa, N. C. A. 1999. O Conhecimento Científico. São Paulo: Discurso Editorial.

Dutra, L. H. de A. 1998. Naturalismo, Falibilismo e Ceticismo. Discurso 29: 15-56.

Friedman, M. 1991. The Re-Evaluation of Logical Positivism. Journal of Philosophy 88: 50519.

- 1999. Reconsidering Logical Positivism. Cambridge: University Press.

1992. Philosophy and the Exact Science: Logical Positivism as a Case Study. In: Earman 1992.

Principia 16(1): 99-119 (2012). 
Giere, R. N. and Richardson, A. W. (eds.) 1996. Origins of Logical Empiricism. Minnesota Studies in the Philosophy of Science. Minneapolis: University of Minnesota Press.

Haack, S. 1995. Evidence and Inquiry. Oxford: Blackwell.

- 1998. Filosofia das Lógicas. São Paulo: Unesp.

Lehrer, K. 1990. Theory of Knowledge. University of Arizona. Westview Press.

Neurath, O. 1983. Philosophical Papers 1913-1946. Ed. and transl. by Robert S. Cohen \& Marie Neurath, (Vienna Circle Collection vol. 16). Dordrecht: Reidel.

Oberdan, T. 1998. Discussion: The Vienna Circle's 'Anti-Foundationalism'. Philosophy. Brit. J. Phil. Sci.: 49: 297-308.

- 1999. Discussion: Deconstructing Protocols: Reply to Uebel. Philosophy. Brit. J. Phil. Sci. 50: 301-4.

-1993. Protocols, Truth and Convention. Amsterdam, Atlanta: Editions Rodopi. 1996.

Poicaré, H. 1984. A Ciência e a Hipótese. Brasília: Editora da UnB.

Quine, W. V. 1985. Dois Dogmas do Empirismo. In: Coleção os Pensadores. São Paulo: Nova Cultural.

Richardson, W. A1998. Carnap's Construction of the World. Cambridge: University Press.

Russell, B. 1995 [1940]. An Inquiry into Meaning and Truth. London and New york: Routledge.

— 1996 [1918]. The Philosophy of Logical Atomism. Chicago and La Salle: Open Court. Schilpp, P. A. (org.) 1963. The Philosophy of Rudolf Carnap. La Salle: Open Court.

Stadler, F. (ed.) 2003. The Vienna Circle and Logical Empiricism: Re-Evaluation and Future Perspectives. Dordrecht: Kluwer Academic Publishers.

- 2003. What is the Vienna Circle? Some Methodological and Historiographical Answers. In: Stadler 2003.

Uebel, T. 1996. Anti-Foundationalism and the Vienna Circle's Revolution. Philosophy. Brit. J. Phil. Sci. 47: 415-40.

- 1999. Discussion: Protocols, Affirmations, and Foundations: Reply to Oberdan. Philosophy. Brit. J. Phil. Sci. 50: 297-300.

- 1992. Overcoming Logical Positivism From Within. Amsterdam, Atlanta: Editions Rodopi B. V.

- (ed.) 1991. Rediscovering the Forgotten Vienna Circle. Austrian Studies on Otto Neurath and the Vienna Circle, (Boston Studies in the Philosophy of Science), Dordrecht: Kluwer.

Wittgenstein, L. 1994. Tractatus Logico-Philosophicus. São Paulo: Edusp.

GELSON Liston

Departamento de Filosofia Centro de Letras e Ciências Humana Universidade Estadual de Londrina Londrina, PR BRASIL

Bolsista Capes-BEX 9362/11-8 gelson@uel.br

Principia 16(1): 99-119 (2012). 
Resumo. Este artigo apresenta uma possível, mas controversa caracterização de dois períodos na obra de Rudolf Carnap: fundacionalismo e antifundacionalismo. Sustentarei que mesmo diante da identificação de dois períodos, é possível argumentar em favor da unidade da obra de Carnap no que se refere à unidade da ciência e ao princípio de tolerância linguística. Para isso, contarei com a análise de algumas teses revisionistas defendidas por Friedman e Uebel. Desta forma pretendo contribuir para uma discussão que, a partir da segunda metade do século xx, parecia ter sido superada, mas que, no final desse mesmo século é retomada devido a importância de temas como o da unidade da ciência, da observabilidade e da interpretação da linguagem científica, para a filosofia da ciência.

Palavras-chave: Fundacionalismo; antifundacionalismo; unidade da ciência; tolerância linguística, revisionismo.

\section{Notas}

${ }^{1}$ Para isso, salientamos a importância do Aufbau, não apenas por ter sido o primeiro grande trabalho de Carnap, mas, principalmente, por ter estabelecido a agenda da filosofia analítica dos anos 20 até sua morte em 1970 (cf. Richardson 1998, p. 5).

${ }^{2}$ A rejeição da metafísica é uma consequência da teoria construcional, sendo os conceitos metafísicos ilegítimos pelo fato de não serem passíveis de construção (e redução) a partir da base empírica do sistema epistemológico.

3 Também é retomado na obra de 1966.

${ }^{4}$ A noção de lógica que Carnap defende no Aufbau, § 107, também é convencional: "a lógica consiste exclusivamente de convenções concernentes ao uso de símbolos, e as tautologias sobre a base destas convenções".

${ }^{5}$ Sobre isso, cf. Dutra 1998, p. 19.

${ }^{6}$ Há outros trabalhos de Carnap, nesse período, que também se caracterizam pelo cunho epistemológico fundacionalista. Todavia, para os nossos objetivos, citamos, neste momento, apenas estes. Na sequência, ao apresentarmos as razões que justificam a classificação do sistema carnapiano como antifundacionalista, citaremos, do mesmo modo, apenas algumas delas.

${ }^{7}$ O sistema cartesiano é um exemplo desse tipo de fundacionalismo (de base).

${ }^{8} \mathrm{O}$ sistema construcional de Carnap representa esse tipo de fundacionalismo (de método), pois ele admite a possibilidade de outras bases. Desse modo, a base fundamental do sistema não é infalível, ou inatacável. Entretanto, uma vez definida a base, o método de construção e de redução é fundacionalista.

${ }^{9}$ A identificação é feita com o falibilismo.

${ }^{10}$ Se tomarmos como exemplo um enunciado universal, ou uma sentença que contenha termos teóricos, como átomos, elétrons, etc., fica claro que a tradução/redução positivista em termos de percepção não é possível (cf. Carnap, 1936-7, p. 466).

${ }^{11}$ Em "Testability and Meaning", Carnap analisa essa alteração como o reconhecimento das limitações da linguagem fenomenológica e um passo à frente, um passo rumo ao fisicalismo: "[... ] o Círculo deu um passo rumo ao fisicalismo, abandonando a linguagem fenomenológica, reconhecendo sua limitação subjetiva" (1936-7, p. 12).

Principia 16(1): 99-119 (2012). 
${ }^{12}$ A negação da certeza empírica não implica que a experiência seja uma ficção, apenas significa que não há experiência imune ao erro.

${ }^{13} \mathrm{Em}$ outra passagem desta mesma obra (p. 38), Carnap relata uma discussão que teve com Einstein sobre a possibilidade de fundamentar o conhecimento a partir dos dados dos sentidos e afirma que tal posição (definir uma base de certeza para o conhecimento - 'rockbottom basis of knowledge') tinha sido abandonada, favorecendo, assim, uma liberalização do empirismo lógico.

${ }^{14}$ De acordo com nossa leitura, as duas citações acima (Carnap, 1963a) - em que Carnap faz referência à base do sistema construcional como uma base de certeza indubitável, sobre a qual os demais enunciados são igualmente decidíveis com certeza - são interpretadas em consonância com o aspecto convencional da teoria construcional, ou seja, uma base aceita como válida.

${ }^{15}$ Sobre a necessidade de um fator externo à linguagem, vale citar Russell e Wittgenstein: Russell (1996, p. 46-7) diz o seguinte: "Para cada fato (supondo, por exemplo, que 'Sócrates está morto' seja um fato) existem duas proposições, uma verdadeira e uma falsa, e não existe nada na natureza do símbolo para nos mostrar qual é a verdadeira e qual é a falsa. Se existisse, poderíamos averiguar a verdade acerca do mundo examinando as proposições sem olhar ao nosso redor". Wittgenstein (1994, aforismo 6.113) afirma: “[... e é também um dos fatos mais importantes que a verdade ou falsidade das proposições não lógicas não possa ser reconhecida na proposição tão-somente".

${ }^{16}$ Ver, por exemplo, a importância do critério factual de redutibilidade no Aufbau §47 e 48. $\mathrm{Ou}$, ainda, em "The Elimination of Metaphysics Through the Logical Analysis of Language", $\S 2$.

Principia 16(1): 99-119 (2012). 